\title{
Editorial to the Special Issue: Towards a New Science of Information - Proceedings of the Fourth International Conference on the Foundations of Information Science, Beijing, August 21-24, 2010
}

\author{
Wolfgang Hofkirchner*, Zong-Rong Li**, Pedro C. Marijuán***, Kang \\ Ouyang ${ }^{* * * *}$
}

* wolfgang.hofkirchner@tuwien.ac.at, Unified Theory of Information (UTI) Research Group, Vienna, Austria ** zrli@hubu.edu.cn, Social Information Science Institute (SISI), Huazhong University of Science and Technology (HUST), Wuhan, P.R. of China

*** pcmarijuan.iacs@aragon.es, Bioinformation Group, Instituto Aragonés de Ciencias de la Salud, Zaragoza, Spain

**** kouyang@mail.hust.edu.cn, Social Information Science Institute (SISI), Huazhong University of Science and Technology (HUST), Wuhan, P.R. of China

In our times, an increasing number of disciplines are dealing with information in very different ways: from the information society and information technology to communication studies (and related subjects like codes, meaning, knowledge, and intelligence), as well as quantum information, bioinformation, the knowledge economy, network science, computer science and the Internet, to name but a few. At the same time, an increasing number of scientists in the East and the West have been engaged with the foundational problems underlying this development, to such an extent that it seems the time has come to integrate disciplines revolving around information. A new science of information can be envisaged that explores the possibilities of establishing a common ground around the information concept, of constructing a new scientific perspective that connects the different information-related disciplines and provides a new framework for transdisciplinary research.

In the beginning of 2010, Zong-Rong Li, Deputy Director of the Social Information Science Institute (SISI) at the Huazhong University of Science and Technology (HUST) in Wuhan, who took the initiative, Wolfgang Hofkirchner, Board Member of the Science of Information Institute (Scil) in Washington, and Pedro C. Marijuán from the board of Foundations of Information Science (FIS) agreed to hold the first-ever scientific conference under the motto "Towards a New Science of Information". SISI took over the role of the host and after just 6 months the conference took place at the Capital Normal University in Beijing as part of the 2010 Multi-Conference on Advanced Intelligence (MCAI 2010) - together with the Second International Conference on Advanced Intelligence (ICAI 2010) and the IEEE Natural Language Processing and Knowledge Engineering (NLP-KE'10) - which was sponsored by the Technical Committee on Artificial Intelligence Theory (TCAIT) of the Chinese Association for Artificial Intelligence (CAAI), Beijing. As the Fourth International Conference of the Foundations of Information Science (FIS 2010) it continued the series of FIS Conferences (Madrid 1994, Vienna 1996, Paris 2005).

It was a great opportunity that this conference could take place in China. Generally speaking, the theoretical study of information as in information science and the practical application of information technology in China are in a beginning phase when compared with Western developed countries. However, with China's rapid development and modernisation, as well as the country's comprehensive application of information science and technology, theoretical study on foundations of information in China is constantly extending and deepening. Scholars from universities and research institutes in Beijing, Wuhan, Xi'an and other places across China actively hold various seminars and workshops and compile research journals to research, discuss and communicate basic theories of 
information science, on the basis of which many works (including books and treatises) are published. SISI was established in 2006. It is a trans-district, trans-affiliation and trans-discipline organisation of theoretical study on information science. In recent years, it held some symposiums and workshops, accepted and granted twenty research projects in the field of social information science proposed by dozens of domestic scholars under the support of the National Philosophy and Social Science Innovation Base named "Scientific Progress and Humanistic Spirit" at HUST. Furthermore, it is also actively concerned with what is termed in China "theoretical informatics and social information problems."

Thus the purpose of the conference was to extend the basis of co-operation in the field of information society, information science and information technology beyond the networks established so far and

- to enable the discussion of different concepts, theories and approaches to the information field,

- to facilitate the exchange between informational disciplines concerning different but complementary tasks, objects of study, and methodologies,

- to network researchers and research institutions as well as knowledge transfer institutions in the promotion of the new science of information,

- to create a new community of scholars and to promote a new style of scholarship, and

- to advance a new point of view on global problems.

In order to accomplish this the conference differed in many respects from previous enterprises.

Firstly, it was open to a broad range of topics:

1. The Impact of a New Science of Information on Society

2. The Position of Intelligence Science in Information Science

a. Information and Intelligence

b. Intelligence Science as an Engineering Informatics in Information Science

3. The Role of Other Applied Information Science Disciplines (Computer Science, Human Computer Interaction, Computer Mediated Communication, Computer Supported Cooperative Work, Information and Communication Technologies and Society, Library and Documentation Science, ...)

4. The Basis of a New Science of Information

a. Feasibility of a single generic concept of information

b. Concepts, Principles, and Methodology of a "General Informatics" or "Theoretical Informatics"

c. Knowledge Structure of a Unified Theory of Information

5. Philosophy of Information

a. Information Ethics

b. Epistemology (Information and the Scientific Method, ...)

c. Ontology of Information

d. Information and Philosophy of Science (Information and the System of Sciences Transdisciplinarity - Consilience, ...)

6. Science of Information in Real-World Systems

a. Science of Information in Physical and Chemical Systems (Quantum Information, Molecular Recognition, ...)

b. Science of Information in Living Systems (Biosemiotics, Systems Biology, Bioinformation, ...)

c. Science of Information in Human / Social Systems

i. Science of Information in Human Cognition (Mind-Brain Theory, Consciousness, ...)

ii. Science of Information in Human Communication (Linguistics, Social Networking, Communication Studies, ...)

iii. Science of Information in Human Cooperation (Collective Intelligence, Knowledge Management, Advanced Intelligence, ...)

7. Science of the Information Society / Age (Information Society Theory, Internet Research, Social Informatics, New Media Studies, ...)

Secondly, a broad range of organisations participated as co-organisers:

CC: Creative Commons License, 2011. 
- Beijing Institute of Graphical Communication, China

- Bertalanffy Center for the Study of Systems Science, Vienna, Austria

- BITrum Research Group, León, Spain

- Center for Information Policy Research, University of Wisconsin, Milwaukee, USA

- Faculty of Economics and Business, University of Maribor, Slovenia

- Institut für Design Science e.V., Munich, Germany

- Institute for Development of Social Responsibility, Maribor, Slovenia

- International Association for Computing and Philosophy (IACAP)

- International Center for Information Ethics (ICIE), Karlsruhe, Germany

- International Center for Transdisciplinary Research (CIRET), Paris, France

- International Society for Biosemiotic Studies (ISBS)

- Molecular Diversity Preservation International (MDPI), Basel, Switzerland

- Symmetrion, Budapest, Hungary

- Unified Theory of Information (UTI) Research Group, Vienna, Austria

- Washington Evolutionary Systems Society (WESS), Washington, USA

Thirdly, a broad range of scholars, all of them dealing with information studies, but representing different appoaches, different institutions or networks, project groups, schools, initiatives, and different countries, many of them being the first time together and in contact with FIS, formed the International Advisory Board of the conference:

- Joseph Brenner (International Center for Transdisciplinary Research, Paris, France)

- Søren Brier (Professor in Semiotics of Information, Cognitive and Communication Science, Department of International Culture and Communication Studies, Centre for Language, Cognition, and Mentality, Copenhagen Business School, Denmark; Executive Committee, ISBS)

- Luis Emilio Bruni (Associate Professor, Department of Architecture, Design and Media Technology, Aalborg University, Denmark; Executive Committee, ISBS)

- Elizabeth A. Buchanan (Director, Center for Information Policy Research, University of Wisconsin, Milwaukee, USA)

- Mark Burgin (Visiting Scholar, Department of Mathematics, University of California, Los Angeles, USA)

- Rafael Capurro (Director, Steinbeis-Transfer-Institute Information Ethics (STI-IE), Germany; Founder, ICIE)

- Jerry Chandler (Research Professor, Krasnow Institute for Advanced Studies, George Mason University, USA; President, WESS)

- John Collier (Professor, Philosophy and Ethics, University of Kwazulu-Natal, Durban, South Africa)

- György Darvas (Senior Research Fellow, Institute for Research Organization, Hungarian Academy of Sciences, Hungary; Director, Symmetrion)

- Mary Jo Deering (Board of Directors, Science of Information Institute, Washington, USA)

- José María Díaz Nafría (Visiting Professor, University of León, Spain; Coordinator, BITrum Research Group)

- Dail Doucette (Director, Science of Information Institute, Washington, USA)

- Charbel Niño El-Hani (Professor of History, Philosophy, and Biology, Institute of Biology, Federal University of Bahía, Salvador, Brazil; Executive Committee, ISBS)

- Charles Ess (Visiting Professor, Department of Information and Media Studies, University of Aarhus, Denmark)

- Peter Fleissner (retired University Professor, Institute of Design and Assessment of Technology, Vienna University of Technology, Austria; UTI Research Group)

- Luciano Floridi (Research Chair in Philosophy of Information, Department of Philosophy, University of Hertfordshire, UK; President, IACAP)

- Klaus Fuchs-Kittowski (retired Professor, Humboldt University Berlin, Germany)

- Ted Goranson (Sirius Beta, USA)

- Jifa Gu (Professor, Academy of Mathematics and Systems Science, Chinese Academy of Sciences)

- Yukio-Pegio Gunji (Professor, Department of Earth and Planetary Science, Graduate School of Science, Kobe University, Japan)

- Soraj Hongladarom (Director, Center for Ethics of Science and Technology, Chulalongkorn Uni- 
versity, Thailand)

- Alicia Juarrero (Professor, Prince George's Community College, USA)

- Kevin G. Kirby (Chair, Department of Computer Science, Northern Kentucky University, USA)

- Klaus Kornwachs (Professor, Philosophy of Technology, BTU Cottbus, Germany)

- Allenna Leonard (President, International Society for the Systems Sciences, Canada)

- Michael Leyton (Professor, DIMACS Center for Discrete Mathematics and Theoretical Computer Science, Rutgers University, USA)

- An-Shun Li (President, Wuhan Wutong-Rain Culture Development Institute, China)

- Shu-Kun Lin (Molecular Diversity Preservation International, Basel, Switzerland)

- Robert K. Logan (Professor Emeritus, Department of Physics, University of Toronto, Canada)

- Ai-Nai Ma (Professor, Peking University, China)

- Shi-Long Ma (Professor, Beijing University of Aeronautics and Astronautics, China)

- Koichiro Matsuno (Professor em., Nagaoka University of Technology, Japan)

- Dong-Sheng Miao (Professor, Renmin University of China, China)

- Matjaz Mulej (former President, International Federation for Systems Research; Institute for Development of Social Responsibility, Maribor, Slovenia)

- Basarab Nicolescu (Professor, Babeş-Bolyai University, Cluj-Napoca, Romania; President, CIRET)

- Toru Nishigaki (Professor, Graduate School of Interdisciplinary Information Studies, University of Tokyo, Japan)

- Michel Petitjean (MTi, INSERM, Université Paris Diderot, France)

- Stuart A. Umpleby (Professor, Department of Management, George Washington University, Washington D.C., USA)

- Günther Witzany (telos, Philosophische Praxis, Bürmoos, Austria)

- Kun Wu (Professor, Xian Jiaotong University, China)

- Tom Ziemke (Professor of Cognitive Science and Cognitive Robotics, Cognition and Interaction Lab, University of Skövde, Sweden)

- Rainer E. Zimmermann (Professor of Philosophy, University of Applied Sciences Munich, Germany; President, Institut für Design Science, Munich)

Fourthly, 80 authors contributed, 45 from China and 35 from abroad. At the conference we could count 63 participants, 34 from China and 29 from abroad.

And last not least, at the conference a committee was established to prepare the founding of an International Society for Information Studies (ISIS) that shall advance global and collaborative studies in the sciences of information, information technology and information society as a field in its own right, elaborate common conceptual frameworks and implement them in practice so as to contribute to mastering the challenges of the information age, and hold conferences in the field every two years. Meanwhile the preparatory committee ended its work and ISIS is to become operative at the same time when these proceedings are published.

Thus we can conclude that the conference was a success. It formed a milestone in the development of the field.

Submissions for the conference underwent a two-step peer review process. Thanks to MDPI who had already sponsored FIS 2005 in Paris, we were provided with an electronic submission and review system. In a first step, only abstracts needed to be uploaded. When accepted, the submitters were invited to upload their full papers for review. Each submission was reviewed by two scholars as a rule. Only in case of doubt a third reviewer was asked. While Wolfgang Hofkirchner was in charge of non-Chinese submissions, Zong-Rong Li established an 8 scholars review committee for Chinese submissions.

For the proceedings presented here all authors of accepted papers were invited to resubmit their papers after the conference. Those who did not seize that opportunity are not included. Several papers had to undergo severe changes. Anthony Hoffmann from the University of Wisconsin, Milwaukee, took the bulk of responsibility in editing the contributions. Finally, we have gathered a number of 31 papers authored by 41 scholars from nearly all over the world (from West to East: USA; Spain, Switzerland, Denmark, Germany, Austria, Sweden, Russia; South Africa; China, Japan). 
We present them in two groups. The first group of papers contribute to the overall theme of the conference and concern questions such as the possibility of unifying approaches, philosophy of information and philosophy of science considerations. The first paper comes from Dail Doucette who introduced to the current discourse the term of a "science of information". The paper is about the future role of such a new transdiscipline in the edifice of scientific disciplines, including social sciences and humanities and arts. In order to implement a science of information José María Díaz Nafría and Francisco Salto Alemany propose a transdisciplinary framework aimed at bridging domains, views, and communities.

John Collier describes the major uses of notions of information in various branches of science and orders them along a nested hierarchy. Miranda Kajtazi and Darek Haftor build upon a comprehensive literature survey of scholarly publications and identify four kinds of information.

A number of contributions try to generalise a certain perspective in order to give an integrative account of information.

One of the most abstract perspectives is the philosophical perspective. In that context it is interesting to learn that China has a tradition of philosophy of information so far not known abroad. Guowu Li describes the lifework of Chinese philosopher of information Kun Wu. Wolfgang Hofkirchner elaborates on a philosophical stance that is requested for a unified theory of information.

While Joseph Brenner's contribution is well founded in philosophy as well, it takes a logical perspective that is on the edge of dialectical logic and formal logic. Another logical approach - with a rather mathematical touch - is pursued by Tian-Qing Qiao.

Mathematician Mark Burgin has developed a general theory of information. His paper discusses mathematical models that establish relations with physics.

Besides philosophical, logical and mathematical perspectives, there are generalisations from natural science angles. After presenting, in a first contribution, a critique of philosopher Fred Dretske's approach to cognition, Díaz Nafría and Mario Pérez-Montoro resort, in a second contribution, to the physics of observation. Also Marcin J. Schroeder stresses the interaction between philosophy and science, when reviewing methodologies for a science of information. In particular, he sees a promising potential in relating to studies of consciousness. Physicist Igor Gurevich gives a physcial account of information. The paper of Jorge Navarro and Pedro C. Marijuán from the Bioinformation and Systems Biology Group at the Aragon Institute of Health Sciences (Zaragoza, Spain) "sees" the world from the point of view of a single cell.

Bin You, educated in bioinformatics, and Zong-Rong Li, working in the field of informatics, compare systems biology and theoretical informatics - the latter term signifies general theories that are part of a science of information. They conclude that systems as well as evolutionary thinking are an essential ingredient of the new science. In the same vein, two Japanese papers from the Graduate School of Interdisciplinary Information Studies at the University of Tokyo - where Toru Nishigaki developed an approach called "Fundamental Informatics" - connect to complex thinking. Wataru Hashimoto tries to redefine the notion of information from a systems perspective, in particular, from the perspective of autopoiesis, and Yohei Nishida discusses the relationship between systems theory and semiotics.

Informatics is more than computer science. So it does not come as a surprise that there are several other authors that start from the paradigm of informatics when heading for the illumination of the phenomenon of information. Kevin Kirby, James Walden, Rudy Garns and Maureen Doyle from Northern Kentucky University look upon the pancomputational turn as modern counterpart of the "great chain of being" originating with Plato. Gerhard Luhn develops an ontology of information that might have implications for computer science. And Konstantin Kolin stresses the importance of dealing with the philosophical problems of informatics.

A second paper of Kolin discusses the social aspects of informatics in a broad sense, called "social informatics" as many Western scholars are accustomed to doing. Vladimir Kinelev highlights the intrinsic relationship between information and education in and for the information society. He sheds a new light on the modern Information and Communication Technologies (ICTs). Another 
important aspect of information is brought to the fore when Luis Emilio Bruni focusses on the relationship of the development of ICTs and sustainability. Also Peter Fleissner sketches a big picture of information society, showing the economic dynamics of information processes in society. These papers demonstrate that the social science approach towards information too is relevant for the further development of a science of information.

Those contributions that deal with particular questions such as those related to specific logical, complexity science, technological or social issues make up the second group. Moto Kamiura analyses abduction as different from deduction and induction articulated by Charles Sanders Peirce with mathematical tools. Eugene S. Kitamura and Yukio-Pegio Gunji's paper uses lattice theory to analyse the behavioural dynamics of characters in literary texts. Lattice theory is also used for analysing double image illusions by the same authors together with Kohei Sonoda, lori Tani and Tomohiro Shirakawa. Jason T. Hewitt uses the rubric of fundamental informatics, a theory of the commons derived from Michael Hardt and Antonio Negri, and Edwina Taborsky's description of the historical transformation of the cultural syntax of museums for humanistic purposes. Bin Yu's contribution is about the social aspects of computer-mediated communication. Yun-Feng Xia characterises the communication system of the internet as a self-organising system. Carlos Aguilar, Lidya Sánchez and Manuel Campos, finally, show how the channel theory of Jon Barwise and Jerry Seligman can be used to describe how audiences extract information from audio-visual contents.

\section{About the Authors}

Wolfgang Hofkirchner

Board member, Science of Information Institute, Washington, DC, USA; Head, Unified Theory of Information (UTI) Research Group, Vienna, Austria; President, Bertalanffy Center for the Study of Systems Science, Vienna, Austria

Zong-Rong $\mathrm{Li}$

Deputy Director, Social Information Science Institute (SISI), Huazhong University of Science and Technology (HUST), Wuhan, P.R. of China

Pedro C. Marijuán

Bioinformation Group, Instituto Aragonés de Ciencias de la Salud, Zaragoza, Spain; Board, Foundations of Information Science

Kang Ouyang

Director, Social Information Science Institute (SISI), Huazhong University of Science and Technology (HUST), Wuhan, P.R. of China; Vice-President, HUST, Wuhan, P.R. of China 